\title{
Determination of wear of surfaces by scratch testing
}

\author{
Witold Brostow ${ }^{1,2}$, Gowrisankar Darmarla ${ }^{1}$, Juliet Howe ${ }^{1}$, Dorota Pietkiewicz $^{1}$ * \\ ${ }^{1}$ Laboratory of Advanced Polymers \& Optimized Materials (LAPOM), Department of \\ Materials Science \& Engineering, University of North Texas, Denton, TX 76203-5310, \\ USA; http://www.unt.edu/LAPOM/; brostow@unt.edu, dorota@unt.edu \\ ${ }^{2}$ Centro de Fisica Aplicada y Tecnologia Avanzada (CFATA), Universidad Nacional \\ Autonoma de Mexico, A.P.1-1010, Queretaro, Qro. 76001, Mexico
}

(Received: April 14, 2004; published: May 3, 2004)

This work has been presented at the $11^{\text {th }}$ Annual POLYCHAR World Forum on Advanced Materials, January 7-10, 2003, in Denton, Texas, USA

\begin{abstract}
We have formulated a quantitative definition of wear different from the current imprecise definitions. Wear is defined as the unwanted loss of solid material from solid surfaces due to mechanical interaction. The debris method currently used to quantify wear produces results strongly dependent on conditions. We have performed multiple scratch tests for a variety of polymer samples: polypropylene, polytetrafluoroethylene and a polyester. In each of the materials studied, the scratch penetration depths reach a constant value at a given force after 8 scratches or so. Similarly, the scratch recovery (final, healing) depths for a fixed force reach a plateau after a dozen or so scratch tests. Thus, strain hardening by repetitive scratching takes place. A likely explanation is formation of a more ordered phase - as seen before in mechanical tests by Siegmann, Aharoni, Faitelson et al. Given these results we define a measure of wear $W(F)$ for a given indenter geometry and force $F$ as $W(F)=\lim _{n \rightarrow \infty} R_{h}(F)$ where $n$ is the number of tests performed and $R_{\mathrm{h}}$ is the final (residual, healing) depth after viscoelastic recovery. The present results confirm also our earlier ones that scratch recovery is another useful way to characterize viscoelasticity.
\end{abstract}

\section{Introduction}

The objective of this work was to find a quantitative definition of wear superior to the current imprecise definitions. Wear can be defined as the unwanted loss of solid material from solid surfaces due to mechanical interaction [1]. The definition implies that wear can be simply determined from the weight or volume of debris (also called wear particles) that separates from the specimen during testing. Either quantity can be made intensive (in the thermodynamic sense, i.e., independent of mass) by dividing the debris weight or debris volume by the contact surface of the specimen. The debris method used currently to quantify wear produces results strongly dependent on testing conditions. This is why we undertook the challenge to develop a new method to serve as a precise measure of wear. 
To appreciate the economic importance of wear, consider this passage from Rabinowicz [2]: "In the late 1960s the British government was persuaded by the Jost Report (1966) that much waste of resources (estimated to be 515 million pounds sterling per year) occurred because of ignorance of mechanical surface interaction phenomena, and a coherent program of education and research was launched to remedy this situation. The word 'tribology' was coined to describe this program and the use of this term has become widespread. The Jost Report actually greatly underestimates the financial importance of tribology. The Report paid little attention to wear, which happens to be (from the economical point of view) the most significant tribological phenomenon."

It seems that none of the extant methods of wear determination has received a general acceptance. Similarly as with friction, wear is much better understood for metals than it is for polymers [2-4]. An 840-page book on polymer testing does not even have the word 'wear' in its subject index [5], although surface wear is important in industry [6] as well as in medical applications of polymers [7]. In general, the connectedness of atoms makes direct application of metal tribology to polymers doubtful.

In recent years numerous attempts have been made to connect hardness to wear. The results are either not very meaningful or even contradict other results along similar lines. There are at least two reasons for this. First, there is a large number of hardness tests [1]; material A will be harder than material $B$ in test $X$, but softer than material B in test $Y$. Briscoe et al. [8] discussed difficulties in achieving mutually consistent hardness values and noted that hardness "may be defined and derived in a number of ways". Second, when performing one kind of test only, one can find that material $\mathrm{C}$ is harder than $\mathrm{D}$, and at the same time there is less wear in C; such a case would confirm the idea of a proportionality of some sort between hardness and wear. However, one can also have material $E$ harder than material $F$, but $F$ undergoes less wear because $E$ is brittle.

Thus, neither polymer science and engineering (PSE) nor materials science and engineering (MSE) as a whole provide a single and reliable procedure for determination of wear. In this situation, we have developed a method to serve as a measure of wear that involves using the micro scratch tester in the multiple scratch determination mode.

\section{Experimental part}

\subsection{Equipment}

We have used a micro scratch tester from CSEM, Neufchatel, Switzerland, utilizing the CSEM Scratch Software Version 2.3, which applies a constantly increasing force from 0 to $15 \mathrm{~N}$ to the samples - or else a constant force. The indenter is of the Rockwell type and consists of a diamond with the point radius of $200 \mu \mathrm{m}$. The scratch speed was $5.3 \mathrm{~mm} / \mathrm{min}$, and the scan length $5 \mathrm{~mm}$. The measured penetration (instantaneous) depths $R_{\mathrm{p}}$ are of the order of microns while the depth determination accuracy is $\pm 7.5 \mathrm{~nm}$. Viscoelasticity is an inherent property of polymers [9], mostly characterized by dynamic mechanical analysis (DMA) [10]. We have found that it manifests itself also in tribology in viscoelastic scratch recovery [11,12]. The process is complete in approximately $3 \mathrm{~min}$. Therefore, after $5 \mathrm{~min}$ a post scan is performed (at the very low load of $0.03 \mathrm{~N}$ ) to measure the residual (healing) depth $R_{\mathrm{h}}$. All reported values are averages of a minimum of ten scratches per sample. 


\subsection{Scratch recovery (healing)}

As mentioned, we have observed viscoelastic scratch recovery before, in synthetic polymers [11] as well as in teeth [12]. The teeth were either bare or had a nanohybrid [13] coating. The major part of a bone including teeth is made up of crystals of hydroxyapatite embedded in a collagen matrix [14]; the mineral phase constitutes $69 \%$ of the total weight, with $9 \%$ water and $22 \%$ organic matrix [15]. Clearly viscoelastic scratch healing occurs in several classes of materials. We have therefore defined [11] the extent of recovery $\Phi$ as

$\Phi=\left(1-R_{\mathrm{h}} / R_{\mathrm{p}}\right) \cdot 100 \%$

\subsection{Single scratch tests}

To develop a useful wear determination technique based on scratch testing, first a number of polymers were investigated. Thus, we have performed single scratch tests on a number of thermoplastic surfaces [11]. More recently we have studied samples from the Technical University of Cartagena of polymers to which small amounts of monomer liquid crystals (MLCs) were added [16,17]: polystyrene (PS); styrene/ acrylonitrile (SAN); and polyamide 6 (Nylon 6, PA 6). The scratch tests provide for a single material thousands of numbers - then converted into Excel files and graphs. Thus, for each sample we obtain diagrams of $R_{\mathrm{p}}, R_{\mathrm{h}}$ and $\Phi$ as a function of the applied force. The respective results are not included here for brevity but constitute a benchmark for multiple scratching experiments.

\subsection{Determination of wear by multiple scratching}

Our equipment allows multiple scratching - which seemed promising. In such tests the residual depth $R_{\mathrm{h}}$ should be a function of the number of scratches made along the same grooves.

Again we were confronted with the issue of the choice of materials - and this time not only differences in chemical structure but also application ranges became important. Polypropylene (PP) is an engineering polymer massively produced, employed in consumer electrical goods, household appliances, and in the home computer market [18]. Thus, PP was our first candidate. Polytetrafluoroethylene (PTFE, Teflon) is also a very popular polymeric material, with a slippery surface - the reason for using it in non-stick cooking utensils. In terms of tribology, Teflon is a material with low friction values, although its scratch resistance is poor [19]. A still different class of polymers are polyesters - such as poly(ethylene terephthalate) (PET) used in soft-drink bottles. We have included a polyester polymer investigated at LAPOM, which has the code name LB-18. The reason for the code is that the project in question involves an industrial company and a non-disclosure agreement.

\section{Multiple scratch testing results}

In each run made at a constant force we obtain a diagram of the depth (penetration or recovery) as a function of location along the path. In all runs the full range was $5 \mathrm{~mm}$. For detailed analysis we have used the depths at $2.5 \mathrm{~mm}$ from the origin, i.e., in the middle of the scratching range. We have thus investigated samples of polypropylene, Teflon, and LB-18. 
The results for polypropylene are shown in Figs. 1 - 3. In Fig. 1 we show the penetration depth $R_{\mathrm{p}}$ curves for several force levels as a function of the number of scratch tests performed. In Fig. 2 we display the healing depth $R_{\mathrm{h}}$ diagrams in the same way. In Fig. 3 we show the extent of recovery as defined by Eq. (1) also as a function of the number of tests.

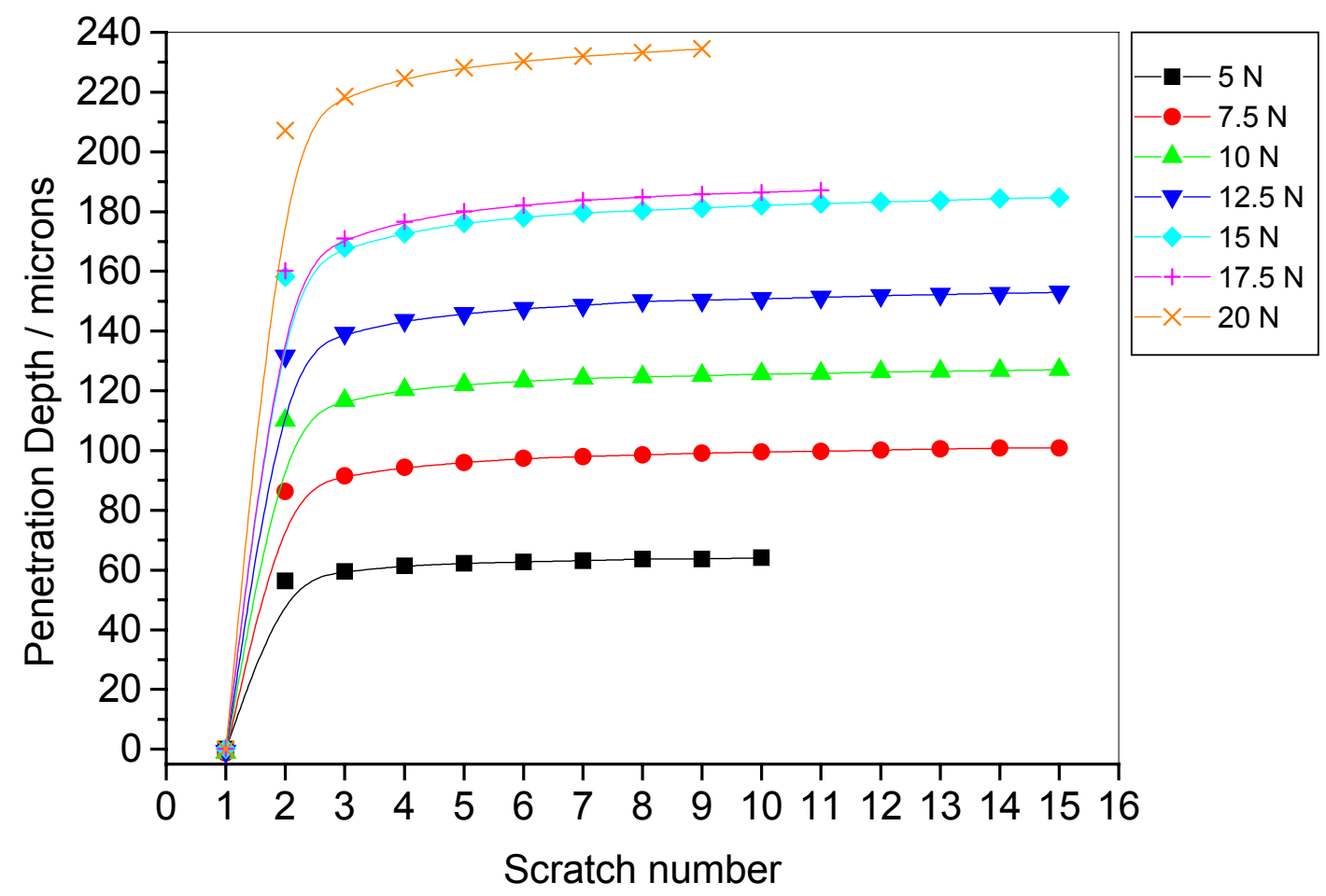

Fig. 1. Penetration depths $R_{\mathrm{p}}$ of polypropylene at several constant force levels as a function of the number of scratching tests performed along a single groove

We see in Fig. 1 that early indentations produce larger effects. The higher the scratch number, the smaller is the effect of scratching with the diamond. As of the run number 8 , the penetration depths for all stress levels reach a plateau. In other words, the following scratches reach exactly the same depth as the run number 8 . The cumulative effect, that is the next scratch reaching deeper than the previous one, has disappeared.

Strain hardening in polymer melts is known, as analyzed for instance for low-density polyethylene by Wagner et al. [20] in terms of entanglements. The results in Fig. 1 prove the existence of strain hardening by repetitive scratching. We shall refer below to strain hardening in solids seen in mechanical testing by several authors. However, since the occurrence of strain hardening does not in principle exclude viscoelastic recovery, we need to see whether the hardening occurs also in the healing diagrams.

In Fig. 2 we see that, at given constant loads, the residual depth $R_{\mathrm{h}}$ gradually increases and with increasing number of tests it reaches an asymptote. The final residual depth asymptote reaches 20 microns under the $5 \mathrm{~N}$ load.

Thus, we find that the strain hardening manifests itself both in the original instantaneous penetration and in recovery. Comparing Figs. 1 and 2, we see that significant recovery occurs. For the force of $20 \mathrm{~N}$ the asymptotic value of $R_{\mathrm{p}}$ is close to $240 \mu \mathrm{m}$ while for the same force the asymptotic $R_{\mathrm{h}}$ is below $120 \mu \mathrm{m}$. 


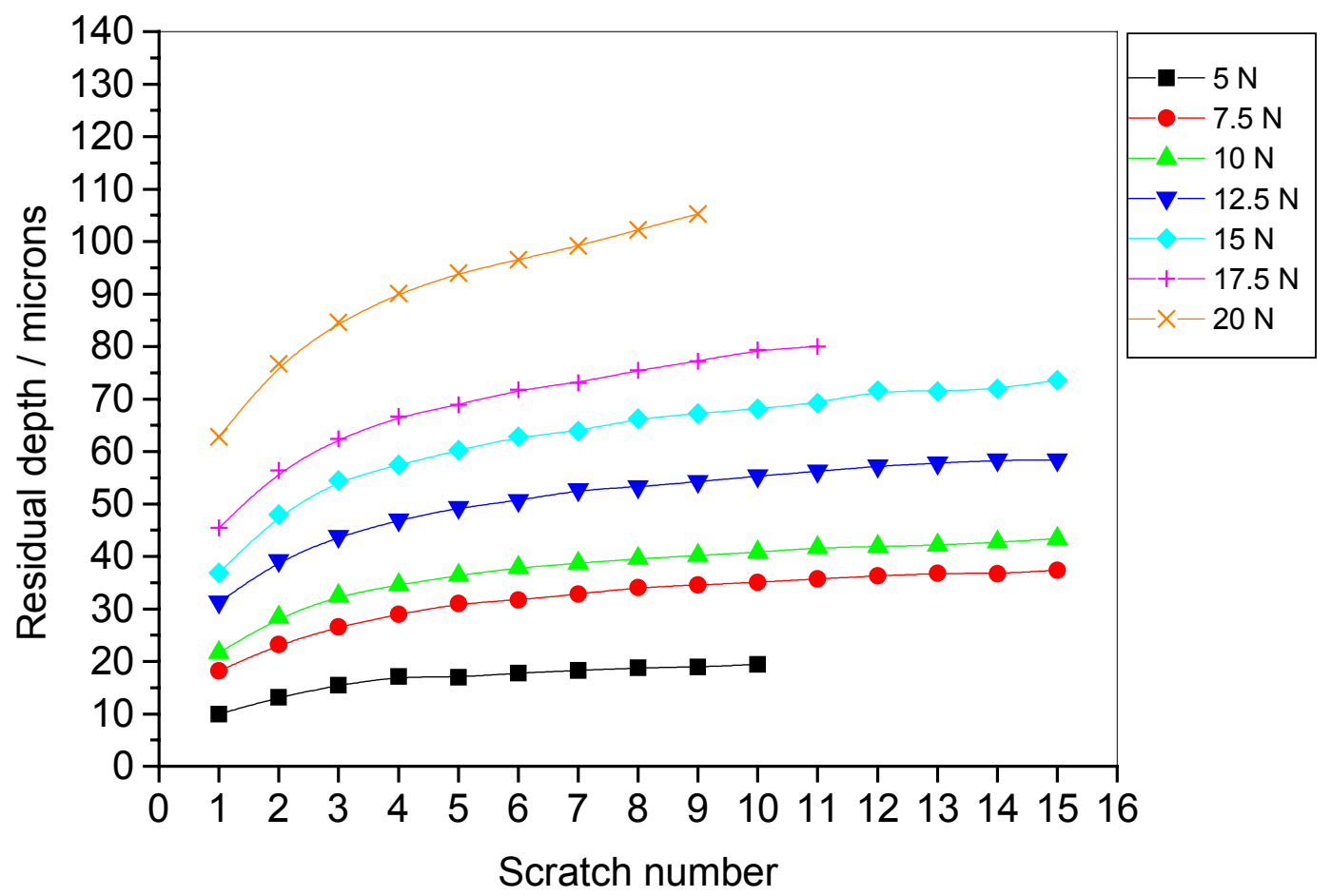

Fig. 2. Residual depths $R_{\mathrm{h}}$ of polypropylene at several constant force levels as a function of the number of scratching tests performed along a single groove

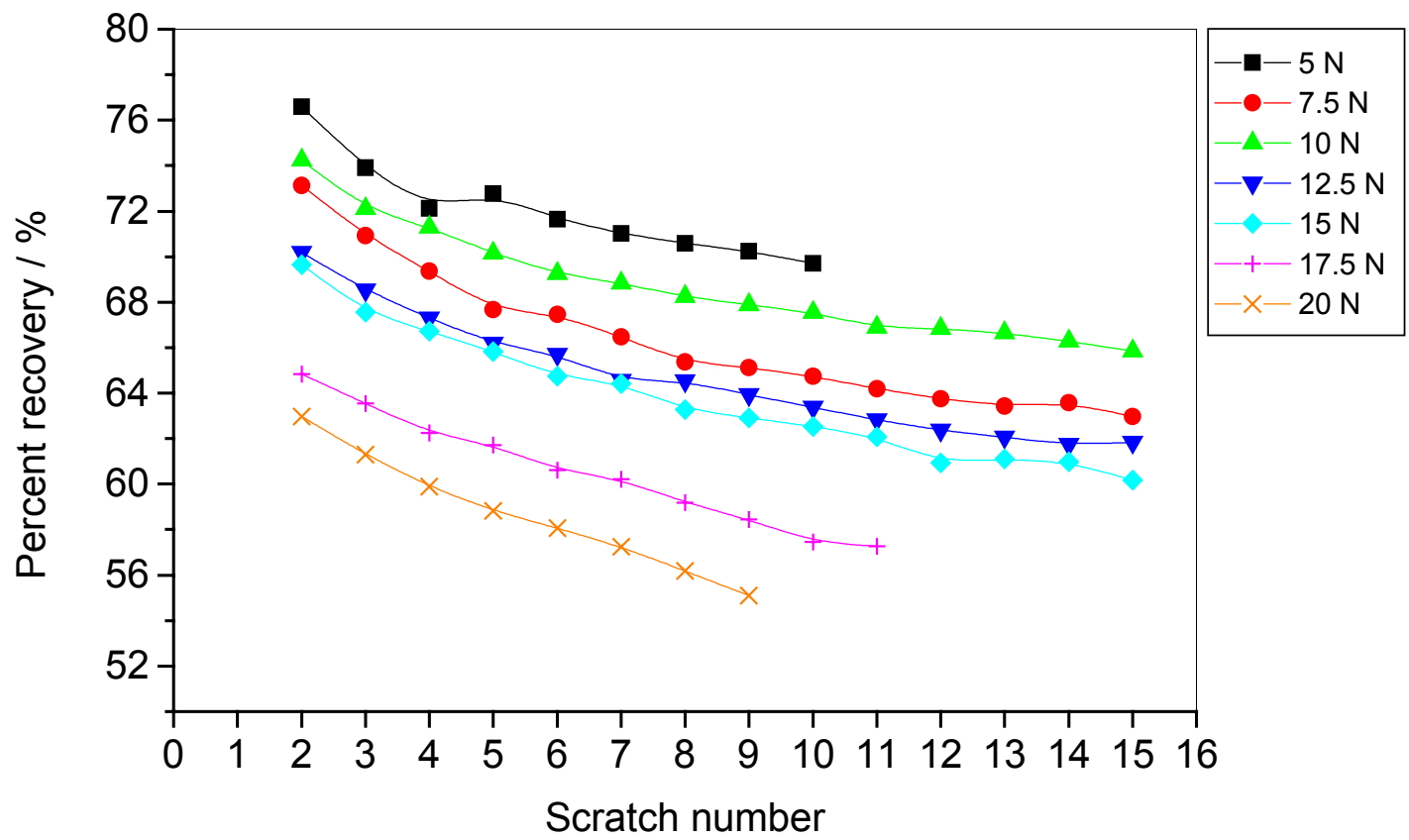

Fig. 3. Percentage recovery of the scratch depth (healing) of polypropylene at several constant force levels as a function of the number of scratching tests performed along a single groove

The extent of recovery $\Phi$ is plotted in Fig. 3. We see that the percentage recovery is the highest in the beginning and then also tends to an asymptote after a dozen or so runs. This is another manifestation of strain hardening.

Since the results for other materials are similar, for brevity we shall include below only the healing depth diagrams. From the point of view of the user these are the 
important ones; the user is interested in the residual depths rather than in the scratching test history. Thus, in Fig. 4 we provide the residual depth results for pure Teflon. It is apparent that the results are qualitatively similar to those for PP, in spite of vastly different chemical compositions (no fluorine in PP, no hydrogen in Teflon). The asymptotic residual depth is at approximately 160 microns for the $25 \mathrm{~N}$ loads, and at $\approx 32$ microns under the $5 \mathrm{~N}$ load. Thus, under the later load, $R_{\mathrm{h}}$ for Teflon is $160 \%$ of the value for PP, testifying to the well-known poor scratch resistance of Teflon.

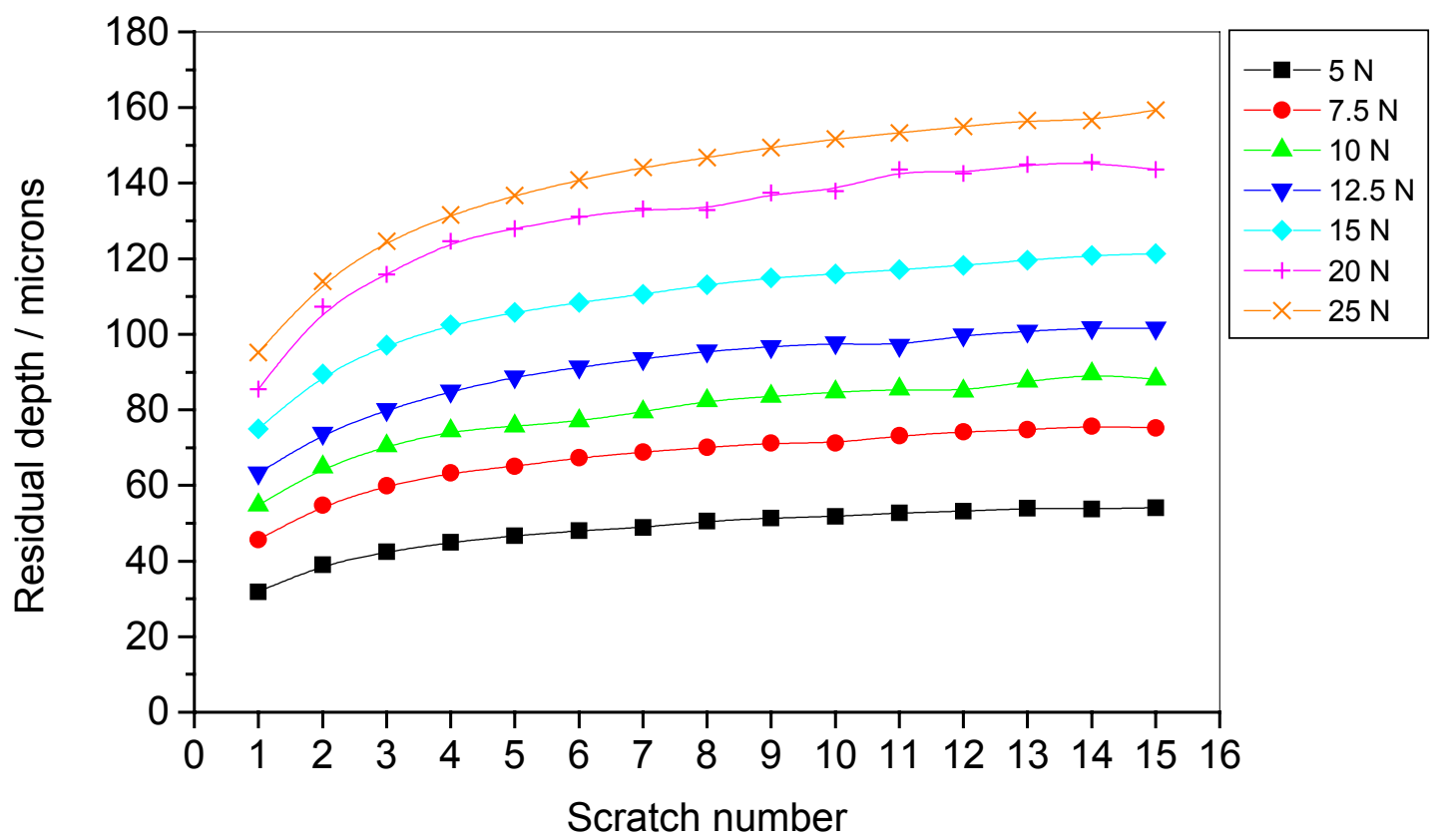

Fig. 4. Residual depths $R_{\mathrm{h}}$ of pure Teflon at several constant force levels as a function of the number of scratching tests performed along a single groove

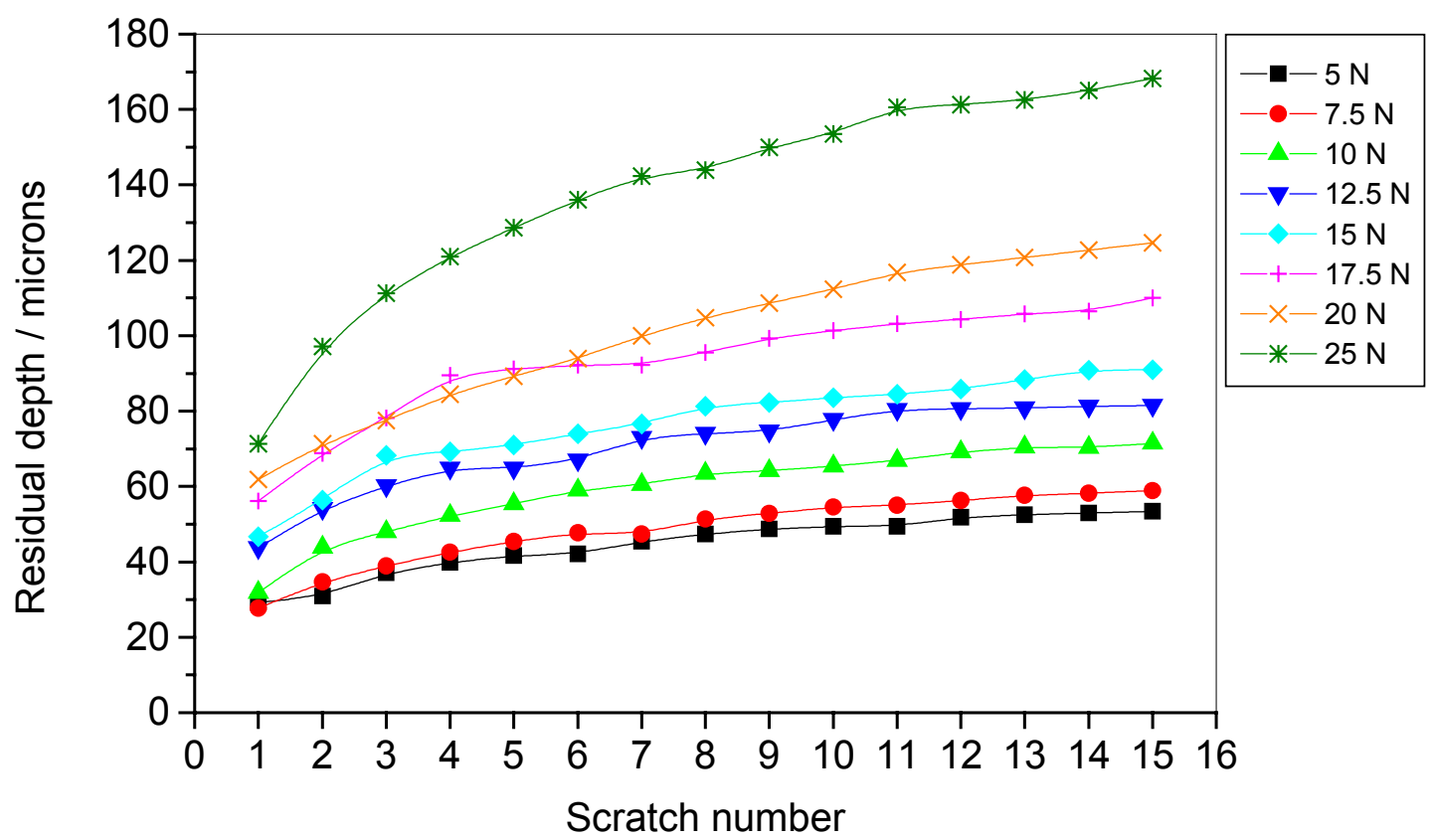

Fig. 5. Residual depths $R_{\mathrm{h}}$ of LB-18 at several constant force levels as a function of the number of scratching tests performed along a single groove 
The results in Fig. 5 for LB-18 are also qualitatively similar to those in previous figures. The final residual depth is at $\approx 170$ microns for the $25 \mathrm{~N}$ load and at $\approx 52$ microns under the $5 \mathrm{~N}$ load. The significance of these results will be discussed in the following section.

\section{Wear determination}

Let us contrast the results displayed above to fatigue [1]: mechanical loading to a relatively low level, but multiple times, eventually leads to fracture. In the present case - apart from the difference between mechanics and tribology - the inverse is true. We see in the figures that consecutive scratch tests produce gradually diminishing deepening of the scratch bottom, leading eventually to a depth that does not change with the number of scratches. We presume that a phenomenon akin to work hardening in metals takes place; the bottom of the scratch 'valley' after several runs represents a high cohesion material with a more ordered structure. We recall work by Diliunas and co-workers on cavities (spheres, cigars) with different structures than the remainder of the polymer [21]. Even more pertinent in this context are the results of Hargett, Siegmann and Aharoni [22,23] who observed formation of more ordered structural units (nodules) with the sizes $\approx 7 \mathrm{~nm}$ in PET upon deformation. Korhov and Faitelson have reported crystallization of epoxies also as a consequence of mechanical deformation [24]. Thus, structural changes resulting from a force application occur in thermoplastic as well as in thermosetting polymers. Since force application is common to mechanics and tribology, apparently response of the material is similar in both cases. Our finding that multiple scratching causes a structural transformation to a stronger material - which then resists scratching - is clearly advantageous.

The multiple scratch results displayed in Figs. 1 - 3 provide for us a basis for a new definition of wear. Given these results, we can define a measure of wear $W(F)$ for a given indenter geometry and force $F$ :

$$
W(F)=\lim _{n \rightarrow \infty} R_{\mathrm{h}}(F)
$$

where $n$ is the number of scratch tests performed. As seen in Figs. $1-3,15$ tests seem to be sufficient, although more tests than 15 have also been made to see whether any further changes occur. We actually stop the experiments when the condition

$$
\left[R_{\mathrm{h}}(n+1)-R_{\mathrm{h}}(n) / R_{\mathrm{h}}(n)\right]<1 \%
$$

is fulfilled.

The measure of wear defined above seems much more precise than the extant definitions. Our measure is connected to a new way of enhancing the scratch resistance of viscoelastic materials. We shall see whether the suggestions embodied in Eqs. (2) and (3) will gain wider acceptance.

Acknowledgement: This work was partly supported by the Robert A. Welch Foundation, Houston (Grant \# B-1203) and also by the Texas Academy of Mathematics and Science through a Summer Research Grant (to J. H.). Comments of the referees on our manuscript are appreciated. 
[1] Brostow, W.; "Science of Materials", Krieger, R. E.; Malabar, F. L.; Brostow, W.; "Einstieg in die moderne Werkstoffwissenschaft", Hanser, München 1985.

[2] Rabinowicz, E.; "Friction and Wear of Materials", $2^{\text {nd }}$ edition, Wiley, New York 1995.

[3] Von Stebut, J.; Lapostolle, F.; Busca, M.; Vallen, H.; Surface \& Coatings Technol. 1999, 160, 116.

[4] Michler, G. H.; "Kunststoff-Mikromechanik: Morphologie, Deformations- und Bruchmechanismen”, Hanser, München 1992.

[5] Brown, R.; “Handbook of Polymer Testing“, Marcel Dekker, New York 1999.

[6] Garbassi, F.; Occhiello, E.; in "Performance of Plastics", Brostow, W.; ch. 16, Hanser, München 2000.

[7] Deng, M.; Shalaby, S. W.; in "Performance of Plastics", Brostow, W.; ch. 23, Hanser, München 2000.

[8] Briscoe, J.; Evans, P. D.; Biswas, S. K.; Sinha, S. K.; Tribology Internat. 1996, 29, 93.

[9] Mark, J. E.; "Physical Properties of Polymers Handbook", American Institute of Physics Press, Woodbury, NY 1996.

[10] Menard, K. P.; “Dynamic Mechanical Analysis”, CRC Press, Boca Raton 1999.

[11] Brostow, W.; Bujard, B.; Cassidy, P. E.; Hagg, H. E.; Montemartini, P.; Mater. Res. Innovat. 2002, 6, 7.

[12] de la Isla, A.; Brostow, W.; Bujard, B.; Estévez, M.; Rodríguez, J. R.; Vargas, S.; Castaño, V. M.; Mater. Res. Innovat. 2003, 7, 110.

[13] Brostow, W.; Castaño, V. M.; Huanosta, A.; de Icaza, M.; Nicho, M. E.; Saniger, J. M.; Mater. Res. Innovat. 1999, 3, 85.

[14] Vincent, J.; "Structural Biomaterials - Revised", Princeton University Press, 1990.

[15] Saenz, A.; Rivera, E.; Brostow, W.; Castaño, V. M.; J. Mater. Ed. 1999, 21, 267.

[16] Bermudez, M. D.; Carrion-Vilchez, F. J.; Cervantes, J. J.; Polym. Internat. 2002, $51,1256$.

[17] Carrion-Vilchez, F.; communication and samples from the Technical University of Cartagena, 2003.

[18] Karger-Kocsis, J.; "Polypropylene”, Chapman \& Hall, London 1999.

[19] Brostow, W.; Bujard, B.; Cassidy, P. E.; Venumbaka, S.; Internat. J. Polym. Mater., to be published.

[20] Wagner, M. H.; Yamaguchi, M.; Takahashi, M. C.; J. Rheol. 2003, 47, 779.

[21] Diliunas, S.; Kleveckas, T.; Liukaitis, J.; Zieleniakiene, D.; Mater. Sci. Medziagotyra 2002, 8, 183.

[22] Harget, P. J.; Siegmann, A.; J. Appl. Phys. 1972, 43, 4357.

[23] Harget, P. J.; Aharoni, S. M.; J. Macromol. Sci. Phys. 1976, B12, 209.

[24] Korhov, V. P.; Faitelson, E. A.; Mech. Compos. Mater. 1993, $29,251$. 